\title{
OSTEOCHONDROMA TALUS: A CASE REPORT
}

\author{
Ch. V. Murali Krishna ${ }^{1}$, P. Ashok Kumar², P. Rambabu³ ${ }^{3}$ K. Srinivasa Rao ${ }^{4}$, M. Satish ${ }^{5}$
}

\section{HOW TO CITE THIS ARTICLE:}

Ch. V. Murali Krishna, P. Ashok Kumar, P. Rambabu, K. Srinivasa Rao, M. Satish. "Osteochondroma Talus: A Case Report". Journal of Evolution of Medical and Dental Sciences 2015; Vol. 4, Issue 03 January 08;

Page: 496-499 DOI: 10.14260/jemds/2015/74

\begin{abstract}
Osteochondroma is one of the most common benign bone tumors. The bones of the feet are less commonly involved and few case reports of osteochondroma involving the talus have been reported so far. Osteochondroma rarely affects talus ${ }^{1}$ and recurrence after excision is rare in younger patients, although recurrences are reported relatively more common in older patients.
\end{abstract}

KEYWORDS: Talus, Osteochondroma.

INTRODUCTION: Osteochondromas are the most common benign osseous neoplasms. These tumors originate from the physis and they are covered by distinct hyaline cartilaginous caps. Osteochondromas or exostosis are abnormal growths of cartilage on the surface of the bone. They are most common bone neoplasms representing 42 to $50 \%$ of all bone tumors. ${ }^{2}$ Growth of the tumor depends on the Patients age and the lesion often becomes quiescent after the closure of growth plate. ${ }^{3}$ Osteochondromas slowly enlarge creating insidious but progressive symptoms. ${ }^{3}$ Although they occur most frequently at the ends of long bones, the involvement of atypical location such as patella or tarsal region has also been reported. Osteochondroma of the talus is very rare and only a few cases have been reported in literature. ${ }^{3}$ The incidence of local recurrence after resection is infrequent and has been reported to be $<2 \%{ }^{4}$

CASE REPORT: We are herewith reporting a case of osteochondroma of the talus in a 12 year old male patient complaining of pain left ankle and had difficulty in walking. He noticed this particular swelling for the last 1 year which was slowly growing and attained a size of $4 \times 5 \mathrm{~cm}$ occupying the anteromedial aspect of talus which is seen from outside below the ankle joint.

On examination, it was a single $4 \times 5 \mathrm{~cm}$ swelling on the anteromedial aspect of talus, hard in consistency and fixed to the underlying bone. In view of the location of the swelling, the movements of the ankle, plantar and dorsiflexion and subtalar movements are restricted. There is no other swelling anywhere in the body. We did a radiographic evaluation and MRI evaluation which showed a solitary pedunculated osteochondroma arising from the body of the talus. MRI also showed a single tumor with a cartilaginous cap of less than $2 \mathrm{~cm}$ and it showed cortical and medullary continuity between the lesion and talar bone which is important for the diagnosis of osteochondroma ${ }^{3}$.

PROCEDURE: Through an anteromedial incision over the swelling, the tumor was exposed all around and the base was clearly exposed. The tumor was excised in toto extra periosteally and sent for histo pathological examination. Biopsy confirmed the diagnosis of osteochondroma.

DISCUSSION: Osteochondromas are solitary / multiple pendunculated or sessile benign outgrowths from bone surface. They are rarely found in the bones of the foot and even less commonly in the talus. ${ }^{2}$ Osteochondromas are usually discovered during the first and second decade of life. ${ }^{2}$ However, 
ostechondromas of the talus are usually discovered in the third and fifth decades. ${ }^{2}$ But in our case we encountered in the second decade itself. Osteochondroma of talus is first reported in 1984 by Fuselier et $\mathrm{al}^{2}$ Chioros et $\mathrm{al}^{2}$ in 1987 reported an atypical osteochondroma from the posterior aspect of talus in a 34 year old male. Again in 2003 Ebler et al reported an osteochondroma arising from the dorsum of talus. But in our case, the location was anteromedial aspect of the body of Talus and occurred in the second decade, which is contrary to the existing reports in the literature. Although, solitary osteochondromas are usually asymptomatic, tumor in the talus may present with variable symptoms including pain, swelling, limitation of movements. ${ }^{3}$

Osteochondroma of talus may also present as a loose body in the ankle joint. ${ }^{3}$ Patients who primarily complain of pain should be informed that there is an increased risk of pain related to surgery or its complications. Considering that $11.6 \%$ of the patients were not fully satisfied with the surgery and that $4.7 \%$ would not have surgery again, we see no justification for the prophylactic excision of asymptomatic osteochondromas. ${ }^{5}$ Surgical indications are pain, disturbance of growth, decreased range of movement, bursitis, peduncle fractures and symptoms secondary to compression of peripheral neuro vascular structures. Major complications and local recurrence are rare.

CONCLUSION: Osteochondroma of the skeleton is common in the age group of thirty years. The osteochondroma in our case involving the talus is at an unusual location and also at twelve years of age. Another significant finding of our case is, it has displaced medial part of the lower tibial epiphysis causing huge gap between the medial malleolus and talus, which was not reported in any of the literature we have reviewed, but still the patient is asymptomatic with full range of ankle movements.

\section{REFERENCES:}

1. Atik OS, Sarikaya B, Kunat C, Muradi R, Ocaktan B, Topçu H. Osteochondroma of the talus. Eklem Hastalik Cerrahisi 2010; 21: 116-7.

2. Kim SH, Chung WY, Kim SH, Lee WS. Osteochondroma of the talus: a report of two cases. J Korean Orthop Assoc 2008; 43: 135-8. Cross Ref.

3. Hakan BOYA OZAL OZCAN, cigdem tokyol Acta orthop trauma tol turk 2014: 48 [2]: 236-239 doi: 10.3944/AOTT. 2014. 3217- Osteochondroma of the talus: an unusual location

4. Molly Schnirring-Judge, DPM, FACFAS, 1 and Jared Visser, DPM2 Resection and Reconstruction of an Osteochondroma of the Hallux: A Review of Benign Bone Tumors and a Description of an Unusual Case. (The Journal of Foot \& Ankle Surgery 48(4):495-505, 2009).

5. Bottner F, Rodl R, Kordish I, Winklemann W, Gosheger G, Lindner N. Surgical treatment of symptomatic osteochondroma. A three- to eight-year follow-up study. J Bone Joint Surg [Br] 2003; 85: 1161-5. 


\section{CASE REPORT}

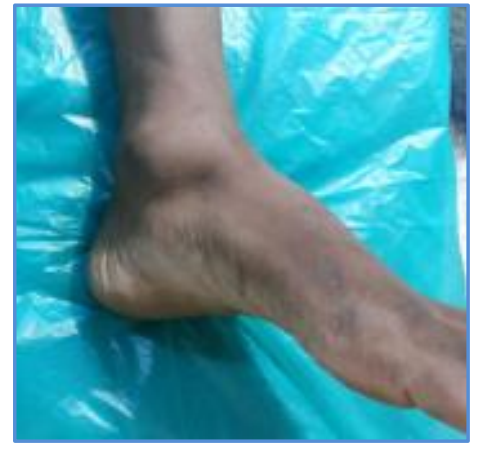

Fig. 1: Pre. Op photo

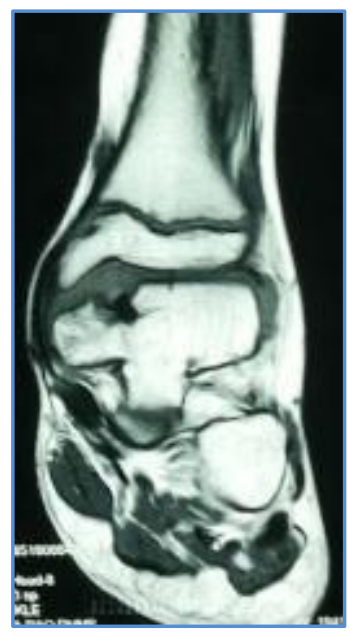

Fig. 3: MRI

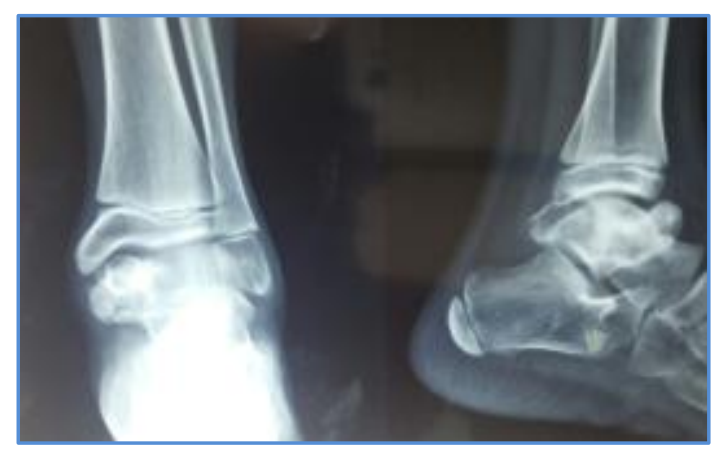

Fig. 2: Pre Op x-ray

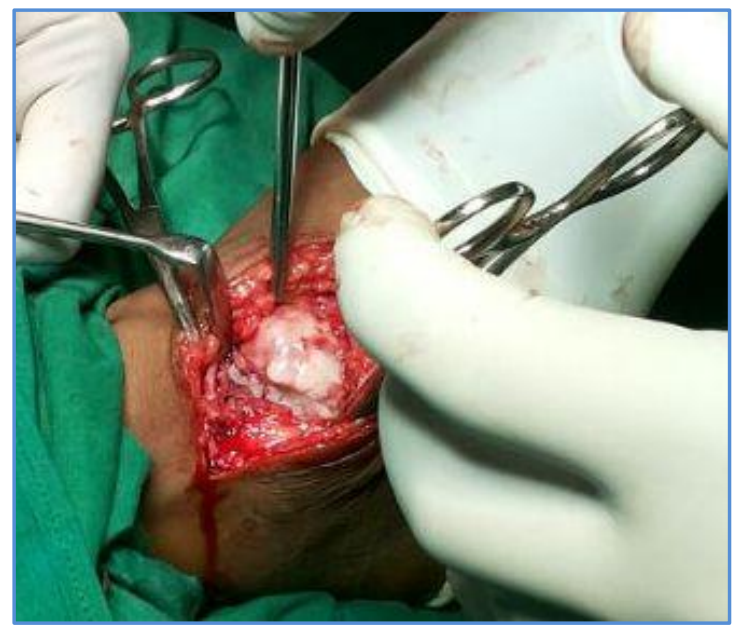

Fig. 4: Intra- op photo

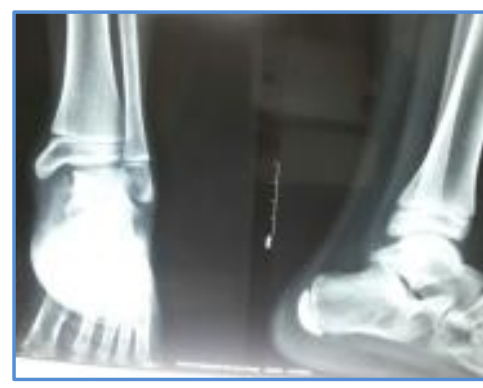

Fig. 5: Post op photo

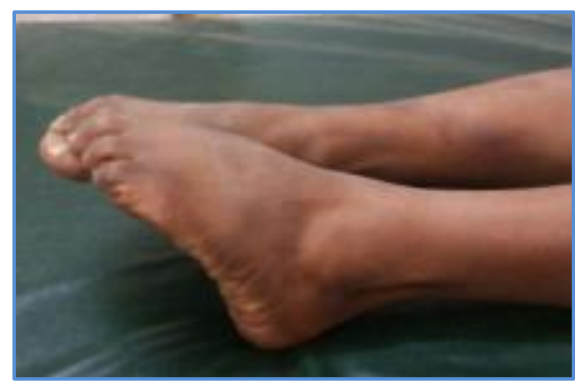

Fig. 6: Follow up movements 


\section{CASE REPORT}

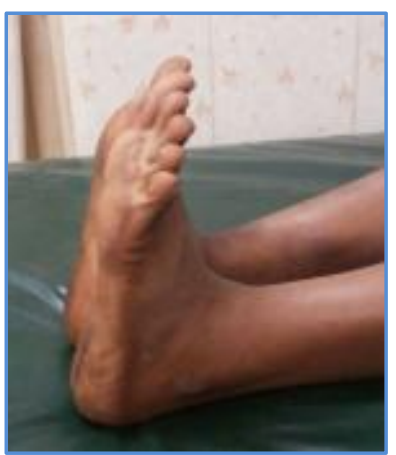

Fig. 7: Follow up movements

\section{AUTHORS:}

1. Ch. V. Murali Krishna

2. P. Ashok Kumar

3. P. Rambabu

4. K. Srinivasa Rao

5. M. Satish

\section{PARTICULARS OF CONTRIBUTORS:}

1. Assistant Professor, Department of Orthopaedics, King George Hospital, Andhra Medical College, Visakhapatnam, Andhra Pradesh.

2. Incharge Professor, Department of Orthopaedics, King George Hospital, Andhra Medical College, Visakhapatnam, Andhra Pradesh.

3. Assistant Professor, Department of Orthopaedics, King George Hospital, Andhra Medical College, Visakhapatnam, Andhra Pradesh.
4. Assistant Professor, Department of Orthopaedics, King George Hospital, Andhra Medical College, Visakhapatnam, Andhra Pradesh.

5. Junior Resident, Department of Orthopaedics, King George Hospital, Andhra Medical College, Visakhapatnam, Andhra Pradesh.

\section{NAME ADDRESS EMAIL ID OF THE CORRESPONDING AUTHOR:}

Dr. P. Ashok Kumar, \# B-98, Dayal Nagar, Visakhapatnam-530043, Andhra Pradesh.

E-mail: ashok_ortho59@rediffmail.com

Date of Submission: 13/11/2014.

Date of Peer Review: 14/11/2014.

Date of Acceptance: 29/12/2014.

Date of Publishing: 08/01/2015. 